\title{
French Diplomas and Skills in European Context
}

\author{
Sandra Safourcade ${ }^{1}$ \\ ${ }^{1}$ University of Rennes 2, Rennes, France \\ Correspondence: Sandra Safourcade, Université de Rennes 2, Campus Villejean, UFR des sciences humaines, \\ Place du recteur Henri le Moal, 35000 Rennes, France. Tel: 3-322-322-5872; 3-366-150-4410. E-mail: \\ sandra.safourcade@univ-rennes2.fr; sandra.safourcade@wanadoo.fr
}

\author{
Received: October 22, 2012 Accepted: November 16, $2012 \quad$ Online Published: July 5, 2013 \\ doi:10.5539/ilr.v2n1p109 URL: http://dx.doi.org/10.5539/ilr.v2n1p109
}

\begin{abstract}
This article aims to present the French educational system and particularly the context of higher education in the process of developing diplomas in a competency-based approach. It aims to establish the underlying models of competence and describe the tools used for European harmonization (Bologna, 1999). It shows how the French model, strongly rooted in its values and culture, has an impact on how the professionalization of students in higher education and how territoriality question support the development of an interface between education and higher socio-economic sector.
\end{abstract}

Keywords: higher education, act, professionalization, diplomas, skill

\section{Introduction}

In the context of actions taken and recommended by Europe to harmonize the European landscape of higher education, the construction of French diplomas sought new approaches to engineering education based on the theoretical model of competency-based approach. The teaching proposed by French higher education must assign an important place to the professional teaching (Companies internship, optional courses ...). It involved taking into account the development of relations with socio-economic sector. On the other part, universities and colleges have to consider the territorial areas and the need to develop learners' skills expected by companies. From a formal point of view, these relations are built by technical support resources and tools developed by France but enrolled in a meta context of the European Qualifications Framework or in future citizen context key skills.

This article aims to analyze, in terms of texts and founding principles concerning the professionalization of French higher education, the construction of higher education diplomas. It wishes to highlight the use of competency-based approach through tools such as the Common Base of Knowledge and Skills, the RNCP (Repertoire National des Certifications Professionnelles) and the ROME (Répertoire Opérationnel des Métiers et des Emplois).

\section{Evolutions of the Professionalization in France Higher Education}

In France, education is ruled by official reference documents such as the B.O.N (French Official Bulletin of National Education), the J.O (French Official Journal of the Education), the Education Code (Code de l'éducation) and the Official Journal of the European Union. The state is actively involved in the structuring, organization and financing of education (human resource management, definition of programs, monitoring quality assurance). The French educational system is governed according centralized approach.

The structuring of the French higher education is based on the introduction of a dual system, the universities and colleges (engineering schools...). These institutions differ in their recruitment of students, more open policy towards universities and more selective recruitment in colleges. In general, French students engaged in higher education pay only the cost of administrative registration. The state supports training costs.

\subsection{French Higher Education: Autonomy and Governance}

Since the Faure law of 12 November 1968, French public universities are places of "functional decentralization of the state" (Bouvier, 2012, p.188). In this line, the Savary Law of 26 January 1984 introducing the reform of higher education creates the "public service of higher education." This law reaffirms the principle of university 
autonomy and unifies the attachment under its authority of the post-secondary educational institutions such as universities and schools. University presidents are not appointed but elected by universities Boards.

The law of 10 August 2007 "Libertés et Responsabilités des Universités" empowers French universities autonomy, including budgetary aspects and human resources management.

In the context of Bologna Process (1999), France is gradually included in the European higher education. It then involved, following official statements of Prague (2001), Berlin (2003), Bergen (2005), London (2007), in training throughout life, the LMD system, the academic recognition of diplomas the European dimension of diplomas, students mobility, internationalization of research, quality and competitiveness of higher education.

\subsection{French Higher Education's Missions}

The public service missions of higher education, under the regulations of Education Code article L. 123-3 are defined by the initial and continuing training, scientific research and technological development, dissemination and exploitation of its results orientation and employability, the dissemination of culture and scientific and technical information, the participation in the construction of the European Higher Education and Research and International Cooperation.

Beyond these tasks, the field of French higher education governed by Education code article L611-2 confronted over the past twenty years the desire and requirements of universities and professional large schools. This article regulates the organization of higher education in connection with the business community. In this context, representatives of various professions, practitioners contribute to teaching as well as the definition of programs that provide a place for internships so professionalizing and recognized in terms of ECTS professional practice tutored students and engineering students in organizations (governments, companies, institutions ...).

The Economic and Social Council in its report of 27/02/2008 relating to the planning and the role of higher education and research recalls the role of the university in the social and economic development of territories enhancement of training and research. Beyond these aspects, the University has positioned itself as a producer of real brainpower, knowledge and heuristic approaches, thus contributing to regional development in terms of regional innovation strategy, effectiveness and career guidance.

\section{Definition and Construction of Diplomas in France}

In France, diplomas under control of the state have different purposes depending on the ministry. Professional degrees are awarded by ministries such as Education or Agriculture for example. The Ministry of Employment broadcast rather titles covering the activities of the world economy (services, industry ...). Branches of industry grouping companies in the same sectors deliver (CQP) certificates of professional qualifications deemed to be an acknowledgment of the ability to exercise a job in the industry. Finally, chambers deliver professional titles similar to specialized certifications (trade, sales ...).

Construction diplomas in France are subject to validation by the National Qualifications established by the Act of 17/01/2002 and placed under the authority of the Ministry of Vocational Training. This committee ensures the adaptation of diplomas and professional field issued by the state (National Education, Higher Education, Ministry of Employment ...), public, private or consular and professional sectors (CQP). Each certificate is registered in the National Directory of Professional Certifications posing a model for the development of standard diplomas highlighting learning outcomes, skills and employability referred audiences' learners. End of 2011, the number of graduates enrolled was 6920 with 2809 for higher education.

A French diploma is built on many parameters: name, nature, duration, accessibility, field, endorsement, specialty courses offered, objectives, target competencies, control mode of knowledge, training accessibility or validation of the experience (VAE), and career opportunities.

The European Qualifications Framework for education and training throughout life (CCC, 2008) is a framework, a meta framework, wishing to make visible, readable and comparable qualifications systems in Europe. It falls in line with the measures adopted by the European Parliament which includes the Bologna process (June 1999) in order to build at an European landscape of higher education based on a harmonization of the higher education system ( Licence-Master-Doctorate) (Safourcade, 2012). In this context, the architecture of French diplomas now gives way to the description and formalization of the competencies targeted by the degree in terms of skills required by the labor market. However, the model underlying the concept of competence as defined does not currently identify standards of competence. 


\section{Underlying Models of Skills}

\subsection{Some Definitions of Skills}

If we go back to the first definitions of skill given by ergonomists whose works tend to describe and explain pofessionnal practices, Montmollin (1984) defines competencies as " stabilized sets of knowledge and know-how, behaviors, standards procedures and reasoning that can be implemented without new learning "(p.122). In 1991 he will establish three components of skill: knowledge, know-how and meta knowledge. Together, these three components can establish how things work, how to operate and how to manage the knowledge acquired during the experiment.

Leplat (1992) identifies five characteristics of skill: finalized, learned, organized, abstract and hypothetical. In order to distinguish between the notions of knowledge, abilities, skills....Leplat highlights two conceptions of competence. The first one, behavioral, combines skill whith context and task performance by an individual. Then a conception associated with cognitive strategy, ie, a "system of knowledge that will lead activity" (Aubret et al, 1993, p. 26).

According to Sorel and Wittorsky (2005) the five components involved in the exercise of skill are the components cognitive, cultural, emotional, social and praxeological. These components interact and articulate with the three micro, meso and macro levels: the individual, the social environment and the organization in which it is inserted.

\subsection{The European Framework for Key Skills}

The European Framework for Key Competences for education and training throughout life (2006) defines a set of key skills related to individuals "fundamental" needs to build and achieve personal and professional projects. In this context, are defined as essential to achieving personal and professional goals of individuals, skills to master the mother language and foreign languages, basic sciences and technologies, information technologies and communication, socialization and citizenship, cognitive and meta-cognitive learning, entrepreneurship and sensitivity.

\subsection{The French Context}

\subsubsection{Emergence of the Skills Approach in France in the Educational System}

In France, the skills approach has emerged in the late eighties in the program of modernization of education and the redefinition of the content of the curriculum.

It is a set of principles for the redesign and implementation of programs within each level of education is consistent with teaching activities. In this set of concepts emerges the concept of competence. This notion then appeared in the school as follows: "The program should not be a stack of knowledge incompatible with the faculties of students. Program at each level must list the skills associated with the acquisition of knowledge and skills corresponding [...] the program explicitly defines the skills necessary final (end of year school cycle or training) and corresponding evaluation methods. ". The notion of competence then rubs the notions of objectives, contract and projects. According Scallon (2004, p.100), "the skills approach is a new approach that differs from pedagogy by objectives".

In 1989, the creation of IUFM (University Institutes for Teacher Training) aims to professionalize the teaching profession. The report attached to the Act of 10 July 1989 states than expected teachers role changes and defines the outline of the profile of the new teacher. "Teachers organize all students activities. They provide courses, tutorials and workshops, participate in students' individual work, perform students' evaluation and assist them in achieving their own project orientation. They support relationships with external partners (parents, businesses, social and cultural outsiders,). They are part of a teacher's team in charge of the same students for a year or a cycle (Robert \&Terral, 2000, p.17). The teacher then leads the class while establishing a communication relationship with students without forgetting its own training and practice analysis.

In this context, the report Bancel (1989) written at the request of the Minister of National Education highlights the professionalism and training of teachers. This report prescribes a lot of skills required to teach and defines teachers professionalism by a set of professional skills (planning pedagogical action, implement a learning situation, control and evaluate the implementation, manage relational phenomena, methodological assistance to students, facilitate students positive professional projects emergence, working in partnership).

In the legislative decree signed on 19 December 2006 (Note 1), Gilles de Robien presents a set of ten skills (act ethically and responsibly in the service of the state, master the French language to teach and communicate, control and disciplines have good general culture, develop and implement teaching, organizing the work of the 
class, taking into account the diversity of students, evaluate students, master information technologies and communication, teamwork and cooperation with parents and school partners, training and innovation throughout his career). Then we note a change in the definition of competence with an opening on new technologies, collective practices and communication with a view to adapting skills to changes in society.

\subsubsection{The Common Base of Knowledge and Skills}

The French system since the Act of April 23, 2005 involving the establishment of a common base of knowledge and skills is based on the European Framework for Key Competences for the determination of student qualifications in compulsory education. The base refers to the Program for International Student Assessment (PISA), which provides a comparative measurement of knowledge and skills throughout life. The common base is available in seven competencies. Five of them are closely related to programs and appeal to different subjects taught in primary school and college: master French language, practice a foreign language, basic skills in mathematics and scientific and technological mastery of the usual techniques of information and communication, humanistic culture. Two other skills, social and civic competences on the one hand and student autonomy and initiative on the other hand are relatively new in the consideration of the assessment of student learning. The base skills are defined as "a combination of fundamental knowledge for present time, the ability to implement in a variety of situations, but also attitudes essential throughout life, such as openness to others, taste for the pursuit of truth, respect for self and others, curiosity and creativity. "

The knowledge base and skills raises the interest of considering all academic disciplines as resources for the acquisition of key competencies. In this sense, it does not affect the programs of primary and secondary but relies on the development of complex situations for observation and assessment of competencies expected of students. The base can be considered as a tool to promote the professionalization of students in their role as students. In this context and in accordance with the importance of observing and promoting the skills of inference situation, teachers provide students with professional academic situations. These are concrete situations in which students will have to mobilize resources and cognitive and psychological conative for an objective problem solving.

This approach is quite favorable to the development of analytical problems and complex situations at school. It will need to be transferred and inferred during secondary and higher vocational education in order to analyze and solve practical business situations

Regarding the traditional education sector in which the requirements in terms of acquiring basic disciplines remain strong, if the common base is not considered as a cognitive approach in which learners do not develop enough knowledge and mobilizations inherently disciplinary knowledge, it may have limitations for further disciplinary courses.

The knowledge and skills common base concerns only the primary and secondary education. Although it does not apply to higher education, this base will then condition, to a certain extent, the driving practices of university teachers and students. Indeed, the goals of the university are maintaining knowledge and professionalism. In the first case, we want to deepen the level of disciplinary knowledge and in the second case, achieving a high level of professionalism requires the need for a strong concepts knowledge.

\subsubsection{The French "ROME" (Operational Directory of Trades and Jobs)}

In a more focused approach on the professionalization of adults, the Operational Directory of Trades and Jobs (ROME) provides 466 trade / job cards bringing 10,000 professional designations. Each card is constructed according to a standardized architecture that defines the name of the job / profession, its general conditions as well as training and experience due to profession exercise skills broken down into specific activities. The cards also state the place activity and working conditions. In this process, the skills required by ROME are defined as basic skills and specific skills. Basic skills at the heart of business are common to all the professional designations of the same card. Specific skills refer to specific work situations.

This conception emphasizes a professional approach authorizing the establishment and construction of the personal project to several professional jobs requiring all the same basic skills but for which specific skills differ depending on contexts. This approach takes into account factors such as contextual and situational factors influence from the implementation of skills in the workplace.

\subsubsection{Skills Conceptualization Adaptation Depending on the Kind of Teaching}

As part of the initial training, the skills underlying model rests on a conception of skill defined as "a group or an integrated set of knowledge, skills and attitudes to be successfully action or a set of actions such as task or work activity. In this approach, the expected skills are then determined as a combination of knowledge, abilities and 
attitudes to do with success, an action or set of actions such as task or work activity". In this approach, the expected competencies are then determined as a combination of knowledge, abilities and attitudes.

Depending on the type more or less technical of the teaching, the skills formalization may go towards the definition of knowledge or abilities. The French educational system is today strongly influenced by five decades of teaching by objectives, also preceded by decades of masterful teaching.

The consequences are the difficulties to consider the role of attitudes and behaviors of students faced with learning and also the formalization of knowledge repositories in a systemic and integrative knowledge and abilities. Consideration of different types of knowledge as potential resources that individual must combine independently to the success of learning is a new concept of teaching learning process. It requires from the teacher or trainer new posture.

In the context of vocational training, the engineering approach training bases initially on the analysis of business situations for designing competency frameworks listing the skills necessary to perform the job in question. On this basis, training standards and evaluation are used to organize training courses and tailored recruitment and assessment of learners and training devices. In this second approach, the type of skills based on two major families, targeting specific skills at the heart of the trade or profession and transferable skills common to several jobs or occupations.

\section{Conclusion}

\subsection{Key Role of Skills in Interface Higher Education / Socio-Economic Sector}

We consider the interface higher education / socioeconomic sector in a triadic approach highlighting three poles: higher education, students and the socio-economic sector. The system reaches stability if we consider each of the three bipolar relations.

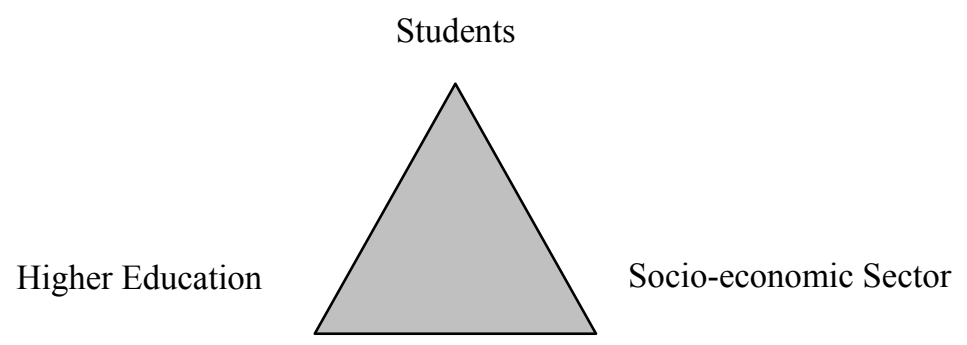

Figure 1. Triadic model

\section{Relationship "Students-Higher Education"}

It reflects the ratio of learners to higher education and vice versa report of higher education to the learner. In a sense, the learner needs to train and acquire at university or in schools of skills required by the labor market. In the other direction, the university's students and offers degrees in terms of skills built also expected by the economic sector.

\section{Relationship "Students - socioeconomic sector"}

Companies, organizations...will find skills they need with students who acquired skills within higher schools.

\section{Relationship "Higher Education-Socioeconomic sector"}

Both organizations need to define together a mode of communication. Companies must identify and explain the skills they expect. They can do this through the ROME. Higher education in turn must invest in the formalization and upgrading of skills it produces within its own organization. It can now rely on the RNCP. These two tools are closely related. Indeed the RNCP refers users to ROME when it comes to defining skills targeted by labor market.

The notion of competence interferes this system by impacting each bipolar relationship. 


\subsection{A French Specificity: The Multidisciplinary Approach of First Level in Higher Schools}

France, during the last few decades, has always trained its student first level of higher education in an inclusive approach involving multiple disciplines for the acquisition and development of knowledge and skills. The current problem is that of inference skills. This has impacted the level of knowledge and adaptability of French learners. For example, the first level training in mathematics involves all the basic sciences such as physics, chemistry, and computer science. The desire to create soon in France first and second year multidisciplinary licenses in human sciences studies is part of the same process. The consequences include the development of professionals maps by responsible for the development of tools and positioning skills certification. These same skills allow access to several employments. Nowadays, individuals are forced many times to change jobs or occupations during their careers. The current education way of thinking can meet this need for flexibility especially among SMEs-SMIs.

\subsection{Higher Education and Professional Programs}

In France, master professional programs allow learners to develop high professional skill. The license level teaching is based on the acquisition of disciplinary and methodological approaches. In his new four-year plan, the Ministry of Higher Education and Research in France has sought to develop "professional licenses" available primarily to students who began their studies within polytechnics (DUT), higher technical patents (BTS) or postgraduate diplomas techniques (DEUST). This choice is guided by the objective to give specialized skills to face the companies' new needs. These diplomas, obtained in one year, involve the active participation of professionals.

\subsection{The Competency-Based Approach: Between National Identity and Common Global Vocational Training}

This article has wished to highlight the notion of competence as understood in the French education system, especially in the context of higher education. The aim was to describe and analyze the French approach to competency-based approach in the construction of diplomas. Then we can see that France, while remaining within the process of European harmonization approach, integrates simultaneously access to skills training and development of academic and professional skills. The role of higher education in its function of transmitting knowledge and capacity development of analysis and synthesis remains deeply rooted in the training programs. Professional skills training are mostly carried out by professionals. This leads to a collaboration of higher education and socio-economic sector.

In an attempt to approach comparative international level, France differs from other countries including the Canadian system strongly attached to the instrumentation of pedagogical action the implementation of steps formalized training engineering contextualized the professional and technical sector. France has therefore entered into the European but remains strongly attached to its culture and values regarding political and educational choices.

\section{References}

Aubret, J., Gilbert, P., \& Pigeyre, F. (1993). Savoir et pouvoir: les compétences en question. Paris: Presses universitaires de France.

Bancel, D. (1989). Créer une dynamique de la formation des maîtres, Rapport de la commission Bancel à L. Jospin, Ministre d'Etat. Paris: MEN.

Bouvier, A. (2012). La gouvernance des systèmes éducatifs. Paris: Presses universitaires de France.

Canadian Methodologic guide. Retrieved from http://www.francophonie.org/IMG/pdf/guide2_final_SB.pdf

Code de l'éducation. Retrieved from http://www.legifrance.gouv.fr

European Qualifications Framework. Retrieved from http://europa.eu/scadplus/leg/fr/cha/c11104.htm

Fiches ROME. Retrieved from http://www2.pole-emploi.fr/espacecandidat/romeligne/RliIndex.do

Jonnaert, P. (2012). Modéliser la compétence pour mieux l'évaluer. Conférence donnée lors du 24e colloque international de l'ADMEE-Europe. 11-13 janvier 2012. Luxembourg.

Leplat, J. (1992). L'analyse du travail en psychologie ergonomique. Toulouse: Octares.

Monchatre, S. (2008). L' « approche par compétence », technologie de rationalisation pédagogique. Le cas de la formation professionnelle au Québec. Net.doc. 36.

Montmollin, M. (1984). L'intelligence de la tâche. Berne: P. Lang.

Répertoire national des certifications professionnelles (RNCP). Retrieved from http://www.rncp.cncp.gouv.fr/ 
Robert, A. D., \& Terral, H. (2000). Les IUFM et la formation des enseignants aujourd'hui. Paris: Presses universitaires de France.

Safourcade, S. (2012). Le cadre européen des certifications et approche par compétence: quels enjeux en France? Weiterbildung, 23, Heft 3, S. 16-18.

Safourcade, S. (2009). Rôle du sentiment d'efficacité personnelle dans l'organisation des pratiques enseignantes: le cas des professeurs de collège. Thèse de doctorat. Université de Toulouse II.

Scallon, G. (2004). L'évaluation des apprentissages dans une approche par compétences. Bruxelles: De Boeck.

Sorel, M., \&Wittorsky, R. (2005). La professionnalisation en actes et en questions. Paris: L'Harmattan.

\section{Note}

Note 1. Arrêté du 19 décembre 2006Bulletin Officiel de l'Éducation Nationale, 1 au 4 janvier 2007.

\section{Copyrights}

Copyright for this article is retained by the author(s), with first publication rights granted to the journal.

This is an open-access article distributed under the terms and conditions of the Creative Commons Attribution license (http://creativecommons.org/licenses/by/3.0/). 